\title{
Awareness and Use of Non Chemical Prevention and Control of Storage Pests of Grains: An International Audience Perpspective
}

\author{
Adebo G.M \\ Department of Agricultural Economics and Extension Services, \\ Ekiti State University PMB 5363, Ado Ekiti Nigeria.
}

O.I Oladele

Department of Agricultural Extension, North West University, South Africa Email: oladele20002001@yahoo.com

\author{
Doi:10.5901/mjss.2014.v5n15p150
}

\begin{abstract}
The study examines the awareness and use of non-chemical methods of prevention and control of storage pests of grains from an international audience perspective. A total of 21 experts that participated in the International research and development course on Food security and grain storage technologies and Management technology training programme in Israel was utilized for the study, while a structured questionnaire was used to elicit information from them. Frequency counts and percentages were used in data analysis, and pie chart was employed in result presentation. Findings confirmed a very high rate of grain loss to storage pests across the globe with most farmers utilizing the chemical control measures only. The use of probe traps is the most common non chemical prevention/ control measures people are aware/ conversant with, followed by the use of light and pheromones while the awareness of the use of food, carton and water are still very low among the respondents. Perception of the applicability of the use of food, pheromones, light and cartons as non-chemical methods of storage pests' prevention and control was very high among the respondents. The study established the relative advantages of the non-chemical control methods over the chemical methods as being cheap, readily available, easily applicable and affordable. It recommends the extensive spread of information on the use of non-chemical control method of storage pests among farmers; capacity building of extension agents and farmers, local manufacture of Probe traps and improved electricity supply to enhance effective utilization of light. Demonstrations of these methods should be made to farmers via multi-media to ensure their adoption.
\end{abstract}

Keywords: Awareness, Grains, Non -Chemical methods, Perception, Storage Pests, Utilization

\section{Introduction}

There is a global increase in the demand for grains for human and animal consumption in recent times. According to Leah et al (2013), population growth and rising incomes in developing countries place pressures on agricultural production to meet the increasing need for affordable food. FAO (2013) report indicates that, globally, 842 million people who represent 12 percent of the global population were unable to meet their dietary requirement in 2011-2013 and that one in eight people in the world are likely to have suffered from chronic hunger. In Africa, one in four people was estimated to be undernourished (FAO, 2013). According to OECD (2008) report, the World prices of wheat, coarse grains, rice and oilseed crops all nearly doubled between the 2005 and 2007 marketing years and continued rising in early 2008. These increases in agricultural commodity prices have been a significant factor driving up the cost of food and have led to a fuller awareness and a justifiably heightened concern about problems of food security and hunger, especially for developing countries. The price hike results from a combination of mutually reinforcing factors such as droughts in key grain-producing regions, low stocks for cereals and oilseeds, increased feedstock use in the production of biofuels, rapidly rising oil prices and a continuing devaluation of the US dollar, the currency in which indicator prices for these commodities are typically quoted as well as the unsettled global economy, which contributed to a substantial increase in speculative interest in agricultural future markets (OECD, 2008, USDA, 2008). According to USDA (2008), the annual growth rate in the production of aggregate grains and oilseeds has been slowing down. The report indicates that, global aggregate grain yield growth averaged 2.0 percent per year from 1970 to 1990, but declined to 1.1 percent from 1990 to 2007. This yield growth is projected to continue to decline by 1.2 percent per year between 2009 and 2017. However, FAOSTAT (2013) latest forecast for the overall World cereal output reveals an upward overall trend of 8.4 
percent in 2013, with a 7.8 percent increase in wheat, 12 percent increase in coarse grains and a slight 1 percent growth expected in rice. Despite the good 2013 cereal outputs, the sub region's aggregate cereal import requirement for the 2013/14 marketing year (July/June) is estimated at 35.9 million tons, similar to the average of the previous five-years. Wheat imports account for almost 60 percent of the total. On average, in the last five years, 45 percent of the total domestic cereal requirements (including food and feed) in Egypt and Morocco were met through imports. The share of imports is even higher in Tunisia (an average of 65 percent), Algeria (68 percent) and Libya (90 percent) (FAOSSTAT, 2013). In 2013, Nigeria imports about 1.6 million metric tons of rice and 3.8 million metric tons of wheat (USDA, 2013, USAID, 2013).

According to Malcolm et al (2013), though the provision of adequate food could be achieved at present for the current global population, it will be very difficult to attain future sustainability due to a steadily increasing population, increased wealth and a diminishing availability of fertile land and water for agriculture and the projected climate change.

All agricultural produce, either of plant or animal origin starts deteriorating almost as soon as they are harvested and it leads to losses. Losses in grain, at times, start from the field and continue during storage. One major factor responsible for grain loss is pest infestation. It has been estimated that between one quarter and one third of the world grain crop is lost each year during storage. Much of this is due to insect attack. In addition, grain which is not lost is severely reduced in quality by insect damage. Many grain pests preferentially eat out grain embryos, thereby reducing the protein content of feed grain and lowering the percentage of seeds which germinate (WAGOV, 2005). According to Donald (1987), over 1 million species of insects inhabit the world, of these species; about 15,000 have detrimental effects which result in losses of $15-20 \%$ of the world agricultural production. According to lliyasu (2013) report, over 30\% of Nigeria's grain output is lost due to spoilage, contamination, and attack by insects and rodents, and physiological deterioration in storage (post-harvest losses). This high loss translates to loss of revenue to Nigeria's peasant farmers.

Attempts to control pests over the years led to the development and use of pesticides. The use of pesticides have been found to accelerate food production globally through increased crop yields and efficiency of food production processes, and have been found to help in controlling the rise in price of food. Pesticides have allowed the consumers to consume high quality produce that is free of insect blemishes and contamination (EPA, 2012). However, pesticides have been found to have destructive effects on human beings. Many pesticides were found to pose risks to people. According to Wikipedia (2013) the uses of organophosphate for instance, was found to have devastating effects on the farmers. Pesticides were found to affect the nervous system, causing skin and eyes irritation, carcinogenic, affecting hormones or endocrine systems as well as reproduction and fetal development (Katarina (2011). Most research findings on reproductive effects of pesticides on farmers working with insecticides in rural areas indicates that male farmers exposed to Organophosphates (OP) were found to have poor semen and sperm quality, low sperm counts per ejaculation, reduced seminal volume and percentage motility while the females suffered from menstrual cycle disturbances, longer pregnancies, spontaneous abortions and stillbirths (Pandit et al, 2011, Leibson and Lifshitz, 2008, Wikipedia, 2013). Prenatal exposure to pesticides has been linked to impaired fetal growth and development. Evidence of OP exposure in pregnant mothers is linked to delayed mental development, Pervasive developmental disorder in the fetus (Eskenazi et al, 1999) and morphological abnormalities in the cerebral surface (Rauh et al, 2011) acute organophosphate and carbamate exposure causes signs and symptoms of excess acetylcholine, such as increased salivation and perspiration, narrowing of the pupils, nausea, diarrhea, decrease in blood pressure, muscle weakness, and fatigue (Pandit et al 2011, Leibson and Lifshitz, 2008). Pesticide exposure can cause a range of neurological health effects such as memory loss, loss of coordination, reduced speed of response to stimuli, reduced visual ability, altered or uncontrollable mood and general behavior, and reduced motor skills((Eskenazi et al, 1999). Acute ingestion of organochlorine insecticides can cause a loss of sensation around the mouth, hypersensitivity to light, sound, and touch, dizziness, tremors, nausea, vomiting, nervousness, and confusion.

Considering the dual global necessity to achieve food security and food safety, most especially in the developing economy, researchers have developed the non-chemical approach to grain storage. Among the non-chemical approaches used involved the use of Light, Pheromones, Food and Probe traps, Cartons and Water. This has been successfully used in Israel (Moshen, 2013). However literature on the practical applicability, in some other countries, is very scarce. Hence the study is carried out to investigate the awareness and use of these non-chemical prevention and control of storage pests of grains from the International audience perspectives.

\section{Methodology}

The population of the study was made up of all the experts that participated in the International research and development course on Food security and grain storage technologies and Management which took place in Israel in 
2013. A total of 21 participants were invited from 12 countries for the training. The countries where the participants were drawn includes: Azerbaijan, China, Guyana, Ghana, Kenya, Laos, Nigeria, Serbia, South Africa, South Sudan, Thailand and Uganda. The entire population formed the sample frame of the study. A structured questionnaire was used to elicit information from them. Data collected was analyzed through the use of frequency counts and percentages, while pie charts were employed in result presentation.

\section{Results and Discussion}

\subsection{Current Rate of Gain Storage Loss}

Data in figure 1 shows that most (50\%) of the countries participants involved in the study indicated that their countries witnessed between 21-30 percent grain storage loss, 30 percent of them indicated 21-30 percent storage loss, 10 percent indicated less than 10 percent grain storage loss, while 5 percent indicated $31-40 \%$ and above $40 \%$ grain storage loss respectively. It could be said that the loss of grains during storage is very high. This is based on the premix that assuming a country produces about 600 tons of corn and about 20 percent of them are lost to storage pests, then it means that 120 tons of the corn is lost. This might be one of the reasons why most developing countries are food insecure, hence the need for engaging different measures of storage pest prevention and control.

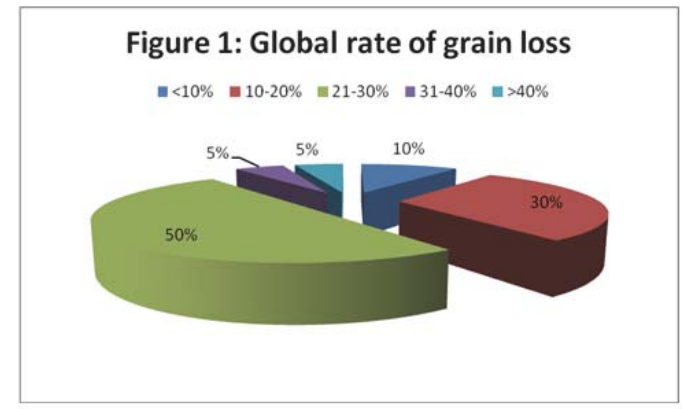

\subsection{Prevention/control measures mostly used across the globe}

Efforts were made to find out the methods of prevention and control measure mostly used across the eleven countries that participated in the survey. Data in figure 2 shows that most of the countries $(80.0 \%)$ engaged in the use of chemical control measure while 20.0percent engaged in the use of both chemical and non chemical control measures. None of the respondents indicated that their country engaged in the use of only the non chemical method of storage pests. It could be affirmed that the use of chemical pest control method of grain pests is prevalent across the globe. This is expected due to the characteristic features of chemicals used in controlling pests such as ready availability, quick actions, easy utilization, and ability to use in the structures, in transit or at silo, in bags/ containers. More also, the use of chemicals have span through the ages. However, recent prevalence of deadly diseases such as cancer, diabetes necessitate the use of alternative methods of preventing/control of grain storage pest

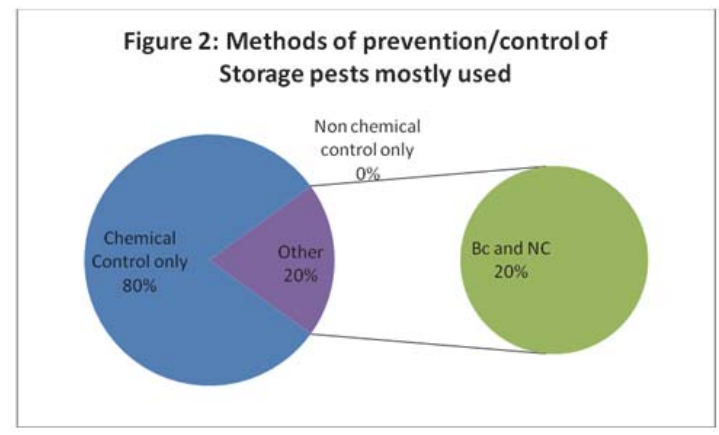




\subsection{Awareness of non chemical prevention and control methods of storage pests}

Data in table 1 shows that $47.60 \%$ of the respondents across eleven countries were aware of the use of light and pheromones in the prevention/control of storage pest; $38.10 \%$ were aware of the use of foods for prevention and control of storage pests; $51.14 \%$ were aware of the use of probe traps while $19.05 \%$ were aware of the use of cartons and water respectively. It could be said that the use of probe traps is the most common non chemical prevention/ control measures people are aware/ conversant with, followed by the use of light and pheromones while the awareness of the use of food, carton and water are still very low among the respondents.

Table 1: Awareness of non chemical prevention and control methods of storage pests

\begin{tabular}{|l|c|c|}
\hline \multicolumn{1}{|c|}{ Variable } & Yes & No \\
\hline Light & $10(47.6 \%)$ & $11(52.4 \%)$ \\
Pheromones & $10(47.6 \%))$ & $11(52.4 \%)$ \\
Food & $08(38.1 \%)$ & $13(61.9 \%)$ \\
Probe traps & $12(51.14 \%)$ & $09(42.86 \%)$ \\
Carton & $04(19.05 \%)$ & $17(80.95 \%)$ \\
Water & $04(19.05 \%)$ & $17.80 .95 \%)$ \\
\hline
\end{tabular}

\subsection{Use of non chemical prevention and control methods of storage pests}

Information on the use of non chemical prevention/control measures as indicated in table 2 shows that $33.33 \%$ of the respondents indicate that their countries engaged in the use of light and pheromones respectively; $38.10 \%$ indicated that their countries engaged in the use of food as a non chemical method of prevention/control of storage pests; 51.14 indicated the use of probe traps while $19.05 \%$ indicated the use of carton and water respectively. It could be affirmed that the use of probe traps is the most common non chemical method of storage pests control used globally. This is expected as information and technologies concerning the use of light, pheromones, food, cartons as well as water as non chemical control methods of storage pests are very scarce. There is the need for a wide information dissemination of these methods. Most of these methods are cheap, effective, easy to use and non toxic if well known among the farmers.

Table 2: Use of non chemical prevention and control methods of storage pests

\begin{tabular}{|l|c|c|}
\hline \multicolumn{1}{|c|}{ Variable } & Yes & No \\
\hline Light & $07(33.33 \%)$ & $14(66.67 \%)$ \\
Pheromones & $07(33.33 \%)$ & $14(66.67 \%)$ \\
Food & $08(38.10 \%)$ & $13(61.90 \%)$ \\
Probe traps & $12(51.14 \%)$ & $09(42.86 \%)$ \\
Carton & $04(19.05 \%)$ & $17(80.95 \%)$ \\
Water & $04(19.05 \%)$ & $1780.95 \%)$ \\
\hline
\end{tabular}

\subsection{Perceived applicability of non chemical prevention and control methods of storage pests}

Data in table 3 shows the perceived applicability of the non chemical prevention and control methods. The non chemical prevention/ control method perceived most applicable to different countries situation is the use of probe traps (80.95\%, this is followed by the use of light and pheromones (76.19\%) respectively, followed perceived the applicability of the use of food for storage pest control; this is followed by the use of food (71.43\%), and the use of carton (52.338\%). The use of water recorded the lowest perceived applicability. In essence, if information, knowledge and skills on the use of food, pheromones, light and cartons as non chemical methods of storage pests prevention and control measures are known to farmers; the possibility of adopting and use them is very high irrespective of the country. 
Table 3: Perceived applicability of non chemical prevention and control methods of storage pests

\begin{tabular}{|l|c|c|}
\hline \multicolumn{1}{|c|}{ Variable } & Yes & No \\
\hline Light & $16(76.19 \%)$ & $05(23.81 \%)$ \\
Pheromones & $16(76.19 \%)$ & $05(23.81 \%)$ \\
Food & $15(71.43 \%)$ & $06(28.57 \%)$ \\
Probe traps & $17(80.95 \%)$ & $04(19.05 \%)$ \\
Carton & $11(52.38 \%)$ & $10(47.62 \%)$ \\
Water & $10(47.62 \%)$ & $11(52.38 \%)$ \\
\hline
\end{tabular}

\section{Conclusion and Recommendations}

The study was carried out to investigate the awareness and use of non chemical; methods of prevention and control of storage pests of grains from an international audience perspectives. The population of the study was made up of all the experts that participated in the International research and development course on Food security and grain storage technologies and Management which took place in Israel in 2014. A total of 21 candidates were invited from 11 countries participated in the training. All these people formed the sample frame of the study. A structured questionnaire was used to elicit information from them while data collected was analyzed through the use of frequency counts and percentages, while pie charts were employed in result presentation. Findings reveals that the rate of grains lost to storage pests in most countries is very high, majority of the farmers engaged the use of chemical control measures only. The use of probe traps is the most common non chemical prevention/ control measures people are aware/ conversant with, followed by the use of light and pheromones while the awareness of the use of food, carton and water are still very low among the respondents. The use of probe traps is the most common non chemical method of storage pests' prevention/ control method used globally. Perception of the applicability of the use of food, pheromones, light and cartons as non chemical methods of storage pests' prevention and control was very high among the respondents. The study established the relative advantages of the non chemical control methods over the chemical methods as being cheap, readily available, easy applicability and affordability. The study recommends the extensive spread of information of the use of non chemical control method of storage pests; capacity building of extension agents in the use of the methods, who in turn is expected train the farmers. Probe traps should be made locally to ensure its availability while the supply of electricity should be improved to enhance the effective utilization of light. Demonstrations of these methods should be shown to farmers via multi-media to ensure their adoption.

\section{References}

Donald (1987): Insects, Isotopes and radiation. Nuclear Techniques for peaceful Development. IAEABulletin. www.iaea.org/publications/magazines/bulletin/bull292/292005580912.pdf

Environmental Protection Agency (EPA, 2012): Benefits of Pesticiedes use. Ag 101/ Agriculture /US /EPA. www.epe.gov/oecaagct/ag101/pestbenefits.html.

Eskenazi B, Bradman A, Castorina R (1999). "Exposures of Children to Organophosphate Pesticides and Their Potential Adverse Health Effects". J Environmental Health Perspectives 107: 409-419

Food and Agriculture Organization (FAO, 2013): Crop prospects and Food Situation. www.fao.org/docrep/019/aq119e/aq119e.pdf.

Food and Agriculture Organization of the United Nations (FAOSTAT, 2013): Production. faostat.fao.org/site/339/default.asp.

Pandit V, Seshadri S, Rao SN, Samarasinghe C, Kumar A, Valsalan R (Jan-Mar 2011). "A case of organophosphate poisoning presenting with seizure and unavailable history of parenteral suicide attempt". J Emerg Trauma Shock 4 (1): 132-4. doi:10.4103/0974-2700.76825. PMC 3097564. PMID 2163

Peiris-John R, Wickremasinghe R (2008). "Impact of low-level exposure to organophosphates on human reproduction and survival". Royal Society of Tropical Medicine and Hygiene 102: 239-245. doi:10.1016/j.trstmh.2007.11.012.3583.

Illiyasu Mohammed Utono (2013): Assessment of Grain loss due to insect pest during storage for small scale farmers of Kebbi. Journal of Agriculture and Vererinary Science pp38-50. www.iosrjournal.org.

Katarina Lah (2011): Effects of pesticides on Human Health. www.toxipedia.org/display/.../Effects+of+Pesticides+on+Human+Health

Leah.M Haris The effects of rising income and inequality

Leibson T, Lifshitz M (2008). "Organophosphate and Carbamate Poisoning: Review of the Current Literature and Summary of Clinical and Laboratory Experience in Southern Israel". J Toxicology 10: 767-7704.

Moshe Kostyukovsky (2013): Integrated Pest Management Lecture notes. International Course on Food Security and Grain storage Technologies and Management. Department of Food Quality and Safety. ARO. The Volcani center, Israel.

OECD (2008): Rising food prices: Causes and Consequences www.oecd.org/trade/agricultural-trade/40847088.pdf.

Rauh V, Arunajadai S, Horton M, et al. (2011). "Seven-year neurodevelopmental scores and prenatal exposure to chlorpyrifos, a 
common agricultural pesticide". Environmental Health Perspective 119: 1189-1195. doi:10.1289/ehp.1003160. PMC 3237355. PMID 21507777.

USDA (2008), Development Dimension of high food prices

USAID, Foreign Agricultural Service ( USDA, 2013): Annual Report 2013 Grains and Feed Annual Nigeria. Global Agricultural Information Network. fas.usda.gov/...grain\%20feed\%20annual_lagod_Nigeria_5..

Western Australian Government (WAGOV, 2005): Insect Pests of Stored Grains. www.agric.wa.gov.au crops post-harvest handling Wikipedia (2013): Neonicotinoid. en.wikipedia.org/wiki/neonicotinoid.

Yurumez Y, Durukan P, Yavuz Y, Ikizceli I, Avsarogullari L, Ozkan S, Akdur O, Ozdemir C (2007). "Acute organophosphate poisoning in university hospital emergency room patients". Intern Med 46 (13): 965-9. PMID 17603234. 